\title{
Are There Sex Differences in Reaction to Different Types of Sexual Infidelity?
}

\author{
T. Joel Wade, Ryan Kelley, Dominique Church \\ Department of Psychology, Bucknell University, Lewisburg, USA \\ Email: t.joel.wade@bucknell.edu
}

Received October 31 ${ }^{\text {st }}, 2011$; revised November $30^{\text {th }}$, 2011; accepted December $25^{\text {th }}, 2011$

\begin{abstract}
Evolutionary theory based research shows that women and men can differ in their responses to sexual and emotional infidelity. However, research has not examined the question of whether men and women react similarly or differently to a partner's engagement in different types of sexual infidelity. The present research sought to answer this question. Based on the aforementioned prior research, and short term mating desires, sex differences in reactions to different types of sexual infidelity were not expected. Both women and men were expected to report higher levels of upset when a partner engaged in sexual intercourse rather than when a partner engaged in oral sex, heavy petting, or kissing with another person. The results were consistent with the hypothesis. Both men and women were most upset by a partner's engagement in sexual intercourse with another person. These findings are discussed in terms of prior research.
\end{abstract}

Keywords: Sexual Infidelity; Oral Sex; Intercourse; Heavy Petting; Kissing

\section{Introduction}

Some research finds that men are more upset by their partner's sexual infidelity while women are more upset by their partner's emotional infidelity (Buss, Larsen, Westen, \& Semmelroth, 1992; Buunk, Angleitner, Oubaid, \& Buss, 1996; Cramer, Abraham, Johnson, \& Manning-Ryan, 2001-2002; Goldenberg, Landau, Pyszczynski, Cox, Greenberg, Solomon, \& Dunnam, 2003; Harris \& Christenfeld, 1996, 1998; Pietrzak, Laird, Stevens, \& Thompson, 2002; Sagarin, Becker, Guadagno, Nicastle, \& Millevoi, 2003; Schützwohl, 2004; Wiederman \& Allgeier, 1993; Wiederman \& Kendall, 1999). Men are more upset by sexual infidelity because it diminishes their paternity certainty and women are more upset by emotional infidelity because it may lead to diminished parental investments from their male partners (Buss et al., 1992; Buss, 1999; Schützwohl, 2004; Symons, 1979; Wiederman \& Allgeier, 1993; Wiederman \& Kendall, 1999). But, this pattern of findings is not very robust (Sabini \& Green, 2004) and some researchers have not found the aforementioned difference (Bassett, 2005; Geary, Rumsey, Bow-Thomas, \& Hoard; 1995; Sabini \& Green, 2004; Sabini \& Silver, 2005; Shackelford, LeBlanc, \& Drass, 2000; Wade \& Fowler, 2006). Additionally, Sagarin (2005) reports that out of 11 studies examining this issue only 4 show significant differences consistent with the aforementioned pattern. Also, the sex difference does not occur when continuous rather than categorical measures are used (Harris, 2003). Furthermore, Mathes (2005) reports that in short term mating contexts both men and women are most upset by a partner's commission of sexual infidelity. Sexual infidelity is more upsetting in short term mating contexts due to the heightened desire for, and competition to, find suitable partners.

While researchers have demonstrated that men and women can differ in what types of infidelity most upset them, no research has examined the question of whether or not sex differ- ences occur in reaction to a partner's commission of different types of sexual infidelity. Would men and women be equally upset by a partner's engagement in intercourse, heavy petting, oral sex, and kissing? Since pregnancy can be a direct result of sexual intercourse one would expect men to be most threatened by a partner's engagement in sexual intercourse with someone else. In addition, following good genes theory where women are most concerned with sexual access and there is heightened competition for sexual access one would also expect women to be most upset about sexual infidelity that involves sexual intercourse since genetic transmission can only occur with intercourse. With this in mind, not surprisingly Greitemeyer (2005) found that women and men view kissing, making out, and switching partners equally. However, Greitemeyer's (2005) research did not examine reactions to sexual infidelity rather it was an investigation of receptivity to sexual offers. Thus, the answer to the question is indefinite. Using a repeated measures design and continuous measures the present research seeks to determine if there are sex differences in responses to different types of sexual infidelity in a short term mating context.

\section{Hypotheses}

Since some prior research has found that men and women are most upset by sexual infidelity (Bassett, 2005; Geary, Rumsey, Bow-Thomas, \& Hoard; 1995; Sabini \& Green, 2004; Sabini \& Silver, 2005; Shackelford, LeBlanc, \& Drass, 2000; Wade \& Fowler, 2006), Greitemeyer (2005) reports that men and women view kissing, making out, and switching partners equally, Mathes (2005) finds that sex differences do not occur in short term mating contexts, and continuous measures are utilized, sex differences are not expected. Men and women are both hypothesized to be most upset about a partner's engagement in sexual intercourse with another individual. 


\section{Method}

\section{Participants}

Participants were 40 women and 39 men ranging in age from 18 to $22, M=19.28, S D=1.03$, recruited from classes on a college campus in the northeastern US. Their participation was in partial fulfillment of course requirements, or voluntary.

\section{Procedure}

Participants were given a questionnaire that included questions regarding their age, sex, and sexual orientation, whether or not they had been in a sexual relationship, what their current relationship status was, whether or not they were on any prescribed medications, or currently taking birth control, and four hypothetical sexual infidelity scenarios: kissing another person, heavy petting with another person, having oral sex with another person, and sexual intercourse with another person. The scenarios were modified versions of scenarios used by Wiederman and Kendall (1999) and Wade and Fowler (2006). The following scenarios were presented to participants in different orders to control for possible order of scenario presentation effects:

\section{Infidelity Scenarios}

It is revealed that your partner kissed someone else passionately, but did not have intercourse with this person. You are sure that your partner still loves you very much and values your relationship. You also realize that what your partner had with this other person was a one time occurrence and that your partner will never see this person again.

$$
\begin{array}{ccccccc}
\begin{array}{c}
1 \\
\text { not upset }
\end{array} & 2 & 3 & 4 & 5 & 6 \begin{array}{c}
7 \\
\text { very upset }
\end{array}
\end{array}
$$

You find out that your partner had sexual intercourse with someone else. You are sure that your partner still loves you very much and values your relationship. You also realize that what your partner had with this other person was a "one-night stand" and that your partner will never see this person again.

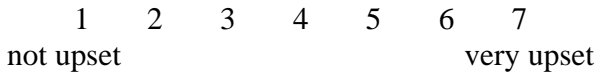

You find out that your partner had oral sex with someone else, but did not have intercourse with this person. You are sure that your partner still loves you very much and values your relationship. You also realize that what your partner had with this other person was a "one-night stand" and that your partner will never see this person again.

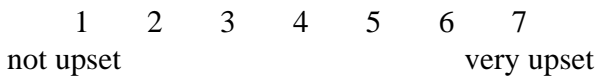

You find out that your partner engaged in some heavy petting with someone else, but did not have sexual intercourse with this person. You are sure that your partner still loves you very much and values your relationship. You also realize that what your partner had with this other person was a one time occurrence and that your partner will never see this person again.

$$
\begin{array}{ccccccc}
1 & 2 & 3 & 4 & 5 & 6 & \begin{array}{c}
7 \\
\text { not upset }
\end{array} \\
\text { very upset }
\end{array}
$$

Participants were instructed to rate their expected level of reaction to each scenario, using a $1=$ not upset to 7 = very up- set scale. Lastly, participants completed a short version of the Marlowe-Crowne Social Desirability Scale to determine whether or not social desirability biases play a role in participants' responses.

\section{Results}

A series of repeated measures ANOVAs across sex of participant, order of scenario presentation, relationship status, medication use, and sexual orientation, were computed. Additionally, participant's social desirability scores were included as a covariate in the analyses. No significant effects occurred for order of presentation, sex of participant, relationship status, medication use, or sexual orientation. In addition, there were no significant effects for social desirability. A significant multivariate effect occurred for infidelity scenario, $F(3,71)=6.43, p$ $<.001$, eta squared $=.28$, observed power $=.96$. This effect was accompanied by a significant univariate effect for scenario, Huynh-Feldt corrected $F(2.43,178.03)=2.44, p<.0001$, eta squared $=14$, observed power $=.998$. Sexual intercourse was perceived as most upsetting $(M=6.45, S D=.99)$, followed by oral sex $(M=6.01, S D=1.17)$, while heavy petting $(M=4.85$, $S D=1.64)$ and kissing $(M=4.58, S D=1.62)$ are least upsetting. Pairwise comparisons with Bonferroni corrections based on the number of comparisons computed revealed that all of the means differ significantly from one another except the means for heavy petting and kissing.

An additional repeated measures ANOVA examining the effect of birth control usage on women participants' responses revealed no significant effect for birth control usage.

\section{Discussion}

The findings were consistent with the hypothesis. The mean levels of upset reported show that sexual infidelity involving sexual intercourse is most upsetting. This is consistent with prior research examining reactions to sexual and emotional infidelity (Bassett, 2005; Geary et al., 1995; Sabini \& Green, 2004; Sabini \& Silver, 2005; Sagarin, 2005; Shackelford et al., 2000, Wade \& Fowler, 2006). This result is a product of the short term context of the infidelity and the mating context for this population. Prior research shows that the mating context for the present sample follows a short term (Flack, Daubman, Caron, Asadorian, D’Aureli, Kiser, Hall, Gigliotti, \& Stine, 2007) and the sexual infidelities in the present research were described such that they indicate a short term liaison. Mathes (2005) reports that both women and men find sexual infidelity more upsetting in a short term context.

The pattern of findings for men can also be explained as a product of male parental investment concerns. Following parental investment theory (Trivers, 1972) men should be most upset by sexual infidelities involving intercourse since intercourse can lead to pregnancy. With a partner's commission of sexual intercourse with another partner men run the risk of being cuckolded in to caring for and raising another man's child. The pattern of findings for women can also be explained as a product of women's short term sexual strategies. Women can engage in short term mating to find good genes, or acquire better mates (Greiling \& Buss, 2000). A partner's commission of sexual intercourse with another diminishes a woman's opportunity to continue to reap genetic benefits or acquire a better mate since she is competing with other women for these same bene- 
fits. Also, such behavior on the part of a partner would not allow a woman the possibility of finding a short term mate that could turn into a long term mate. Buss and Schmitt (1993) report that women can use short term mating to test for/find long term mates.

\section{Limitations and Future Study}

Since the present research involved hypothetical responses to infidelity scenarios future research should examine the responses of men and women who have actually experienced the various types of sexual infidelity. Also, since an individual's mate value characteristics can affect feelings of jealousy experienced (Brown \& Moore, 2003), future research should also examine how men and women's mate value characteristics as well as their rivals' mate value characteristics affect feelings of jealousy experienced with different types of sexual infidelity. Additionally, the sample included in this research is from the same shared environment which could influence their responses. Therefore, additional research with samples from diverse environments should be conducted. Since culture can interact with evolutionary adaptations (Buss, 1995; Crawford \& Anderson, 1989) it is possible that in other environments the degree of similarity in responding may be lower. Similarly, future research should examine how the characteristics of rivals affect men and women of different cultures' responses to the various types of sexual infidelity.

\section{REFERENCES}

Bassett, J. F. (2005). Sex differences in jealousy in response to a partner's imagined sexual or emotional infidelity with a same or different race other. North American Journal of Psychology, 7, 71-84.

Brown, W. M., \& Moore, C. (2003). Fluctuating asymmetry and romantic jealousy. Evolution and Human Behavior, 24, 113-117. doi:10.1016/S1090-5138(02)00148-4

Buss, D. M. (1995). Psychological sex differences: Origins through sexual selection. American Psychologist, 50, 164-168. doi:10.1037/0003-066X.50.3.164

Buss, D. M. (1999). Evolutionary psychology: The new science of the mind. Massachusetts: Allyn \& Bacon.

Buss, D. M., Larsen, R. J., Westen, D., \& Semmelroth, J. (1992). Sex differences in jealousy: Evolution, physiology, and psychology. Psychological Science, 3, 251-155. doi:10.1111/j.1467-9280.1992.tb00038.x

Buss, D. M., \& Schmitt, D. P. (1993). Sexual strategies theory: An evolutionary perspective on human mating. Psychological Review, 100, 204-229. doi:10.1037/0033-295X.100.2.204

Buss, D. M., Shackelford, T. K., Kirkpatrick, L. A., Choe, J. C., Lim, H. K., Hasegawa, M., Hasegawa, T., \& Bennett, K. (1999). Jealousy and the nature of beliefs about infidelity: Tests of competing hypotheses about sex differences in the United States, Korea, and Japan. Personal Relationships, 6, 125-150. doi:10.1111/j.1475-6811.1999.tb00215.x

Buunk, B. P., Angleitner, A., Oubaid, V., \& Buss, D. M. (1996). Sex differences in jealousy in evolutionary perspective: Tests from the Netherlands, Germany, and the United States. Psychological Science, 7, 359-363. doi:10.1111/j.1467-9280.1996.tb00389.x

Carlson, R. A., \& Willis, F. N. (1993). Singles ads: Gender, social class, and time. Sex Roles: A Journal of Research, 29, 387-405. doi:10.1007/BF00289431

Cramer, R. E., Abraham, W. T., Johnson, L. M., \& Manning-Ryan, B. (2001-2002). Current psychology: Developmental, learning, personality, social. 20, 327-336. doi:10.1007/s12144-001-1015-2

Crawford, C. B., \& Anderson, J. L. (1989). Sociobiology: An environmental discipline? American Psychologist, 44, 1449-1459.
doi:10.1037/0003-066X.44.12.1449

Flack, W. F., Daubman, K. A., Caron, M., Asadorian, J., D’Aureli, N., Kiser, S., Hall, A., Gigliotti, S., \& Stine, E. (2007). Risk factors and consequences of unwanted sex among university students: Hooking up, alcohol, and stress response, Journal of Interpersonal Violence, 22, 139-157. doi:10.1177/0886260506295354

Geary, D. C., Desoto, M. C., Hoard, M. K., Sheldon, M. S., \& Cooper, M. L. (2001). Estrogens and relationship jealousy. Human Nature, 12, 299-320. doi:10.1007/s12110-001-1001-2

Geary, D. C., Rumsey, M., Bow-Thomas, C. C., \& Hoard, M. K. (1995). Sexual jealousy as a facultative trait: Evidence from the pattern of sex differences in adults from China and the United States. Ethology and Sociobiology, 16, 355-383. doi:10.1016/0162-3095(95)00057-7

Goldenberg, J. L., Landau, M. J., Pyszczynski, T., Cox, C. R., Greenberg, J., Solomon, S. \& Dunnam, H. (2003). Gender-typical responses to sexual and emotional infidelity as a function of mortality salience induced self-esteem striving. Personality and Social Psychology Bulletin, 29, 1585-1595. doi: $10.1177 / 0146167203256880$

Greiling, H., \& Buss, D. (2000). Women's sexual strategies: The hidden dimension of extra-pair mating. Personality and Individual Differences, 28, 929-963. doi:10.1016/S0191-8869(99)00151-8

Greitemeyer, T. (2005). Receptivity to sexual offers as a function of sex, socioeconomic status, physical attractiveness, and intimacy of the offer. Personal Relationships, 12, 373-386. doi:10.1111/j.1475-6811.2005.00121.x

Harris, C. R. (2003). A review of sex differences in sexual jealousy, including self-report data, psychophysiological responses, interpersonal violence, and morbid jealousy. Personality and Social Psychology Review, 7, 102-128. doi:10.1207/S15327957PSPR0702_102-128

Harris, C. R., \& Christenfeld, N. (1996). Gender, jealousy, and reason. Psychological Science, 7, 364-366. doi:10.1111/j.1467-9280.1996.tb00390.x

Mathes, E. W. (2005). Relationship between short-term sexual strategies and sexual jealousy. Psychological Reports, 96, 29-35. doi:10.2466/pr0.96.1.29-35

Pietrzak, R. H., Laird, J. D., Stevens, D. A., \& Thompson, N. S. (2002). Sex differences in human jealousy: A coordinated study of forcedchoice, continuous rating-scale, and physiological responses on the same subjects. Evolution and Human Behavior, 23, 83-94. doi:10.1016/S1090-5138(01)00078-2

Sabini, J., \& Green, M. C. (2004). Emotional responses to sexual and emotional infidelity: Constants and differences across genders, samples, and methods. Personality and Social Psychology Bulletin, 30, 1375-1388. doi:10.1177/0146167204264012

Sabini, J., \& Silver, M. (2005). Gender and jealousy: Stories of infidelity. Cognition and Emotion, 19, 713-727.

Sagarin, B. J. (2005). Reconsidering evolved sex differences in jealousy: Comment on Harris (2003). Personality and Social Psychology Review, 9, 62-75. doi:10.1207/s15327957pspr0901_5

Sagarin, B. J., Becker, D. V., Guadagno, R. E., Nicastle, L. D., \& Millevoi, A. (2003). Sex differences (and similarities) in jealousy. The moderating influence of infidelity experience and sexual orientation of the infidelity. Evolution and Human Behavior, 24, 17-23. doi:10.1016/S1090-5138(02)00106-X

Schützwohl, A. (2004). Which type of infidelity makes you more jealous? Decision strategies in a forced-choice between sexual and emotional infidelity. Evolutionary Psychology, 2, 121-128.

Shackelford, T. K., LeBlanc, G. J., \& Drass, E. (2000). Emotional reactions to infidelity. Cognition and Emotion, 14, 643-659. doi:10.1080/02699930050117657

Symons, D. (1979). The evolution of human sexuality. New York: Oxford University Press.

Trivers, R. (1972). Parental investment and sexual selection. In B. Campbell (Ed.), Sexual selection and the descent of man (pp. 136-179). New York: Aldine DeGruyter.

Wade, T. J., \& Fowler, K. (2006). Sex differences in responses to sexual and emotional infidelity: Considerations of rival attractiveness and financial status. Journal of Cultural and Evolutionary Psychol- 


\section{T. J. WADE ET AL.}

ogy, 4, 37-50. doi:10.1556/JCEP.4.2006.1.3

Wiederman, M. W., \& Allgeier, E. R. (1993). Gender differences in sexual jealousy: Adaptionist or social learning explanation? Ethology and Sociobiology, 14, 115-140. doi:10.1016/0162-3095(93)90011-6
Wiederman, M. W., \& Kendall, K. (1999). Evolution, sex, and jealousy: Investigation with a sample from Sweden. Evolution and Human Behavior, 20, 121-128. doi:10.1016/S1090-5138(98)00046-4 